\title{
Investigation of Erosion of Cement-Bentonite via Piping
}

\author{
Zijun Wang, ${ }^{1}$ Boming Zhao, ${ }^{1}$ and A. C. D. Royal ${ }^{2}$ \\ ${ }^{1}$ School of Civil Engineering, Beijing Jiaotong University, Beijing, China \\ ${ }^{2}$ School of Civil Engineering, University of Birmingham, Edgbaston, Birmingham, UK \\ Correspondence should be addressed to Boming Zhao; bmzhao@bjtu.edu.cn
}

Received 2 July 2017; Accepted 14 August 2017; Published 28 September 2017

Academic Editor: Francesco Ruffino

Copyright (C) 2017 Zijun Wang et al. This is an open access article distributed under the Creative Commons Attribution License, which permits unrestricted use, distribution, and reproduction in any medium, provided the original work is properly cited.

\begin{abstract}
Cement-bentonite is one of the main materials used in the seepage barriers to protect earth dams and levees from water erosion. However, the current understanding of the erodibility of the cementitious materials and the interactions between cracked seepage barriers and the water flow is inadequate. Based on the laboratory pinhole erosion test, we first investigated the impacts of cementbentonite treatments by using the ground granulated blast-furnace slag (GGBS) as replacement on the erosion characteristics, compared with the original mixtures; the inclusion of GGBS highlighted a potential advantage against water erosion. In addition, we proposed to calculate the erosion percentage and establish the mathematical relationships between the erosion percentage and different regimes, that is, different curing period, erosion time, and sizes of initial holes. Results showed that enough curing period was critical to avoid the increases of hydraulic conductivity in the macrofabric of the barrier; meanwhile, the materials were eroded quickly at the beginning and slowed down with the erosion time, where the enlargement of the initial creaks would be stabilised at some point in time. Moreover, the sizes of initial holes may affect the erosion situation varying from the sample curing periods.
\end{abstract}

\section{Introduction}

Seepage barriers are often used in earth dams and levees to reduce the water flow through their foundations or embankments $[1,2]$. However, internal erosion is known to occur in these seepage barriers and the ability of predicting this kind of piping has been inadequate and leads to many failures $[3,4]$. Govindaraju et al. [5] concluded that the internal erosion and piping process consists of the particle detachment and subsequent migration. The initiation of a pipe is generally considered to originate from a concentrated leak and the pipe formation often progresses from the downstream to upstream face [6]. There are two parameters affecting the pipe development: the strength of soil structures and the sufficient seepage flow to overcome the critical shear strength between particles for erosion and transportation [7].

Cement-bentonite is one of the main materials used in seepage barriers $[8,9]$; in addition, to achieve the recommended hydraulic conductivity and maintain a slurry that is pumpable and economic, the cement replacement materials such as pulverised fuel ash (PFA) and ground granulated blast-furnace slag (GGBS) are commonly required [10, 11]. However, the current understanding of the erodibility of these materials and the interactions between cracked seepage barriers and the water flow is inadequate, where limited data was available to provide the sufficient information regarding the impacts of cement replacements, curing period, erosion time, and sizes of initial cracks.

Based on the laboratory pinhole erosion test [12], which can be a convenient method to quantify the material erodibility, this paper investigated the impact of cement-bentonite treatments on erosion characteristics. In addition, the hole erosion test $[13,14]$ was also referred to simulate the erosion phenomenon in open cracks. In the following sections, the testing procedures and theoretical models were presented; then we proposed to calculate the erosion percentage and establish the mathematical relationships between the erosion percentage and different regimes, that is, different cementitious replacement, curing period, erosion time, and sizes of initial holes to aid in assessing the internal erosion propagating from cracks in cement-bentonite seepage barriers. 

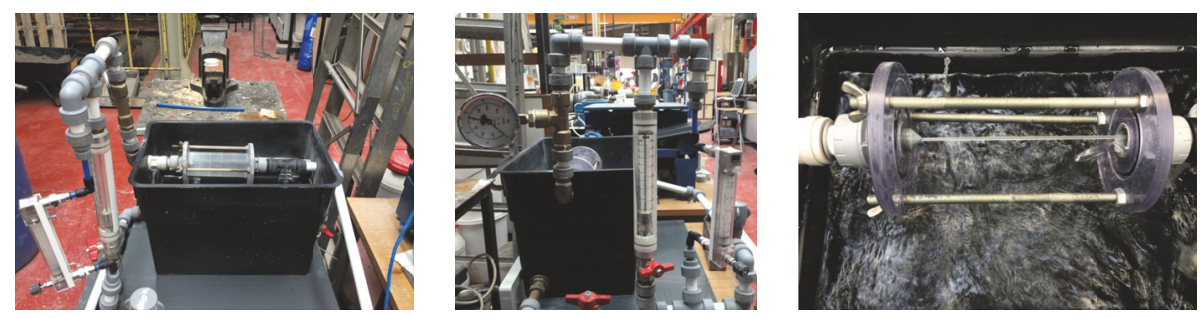

(a)

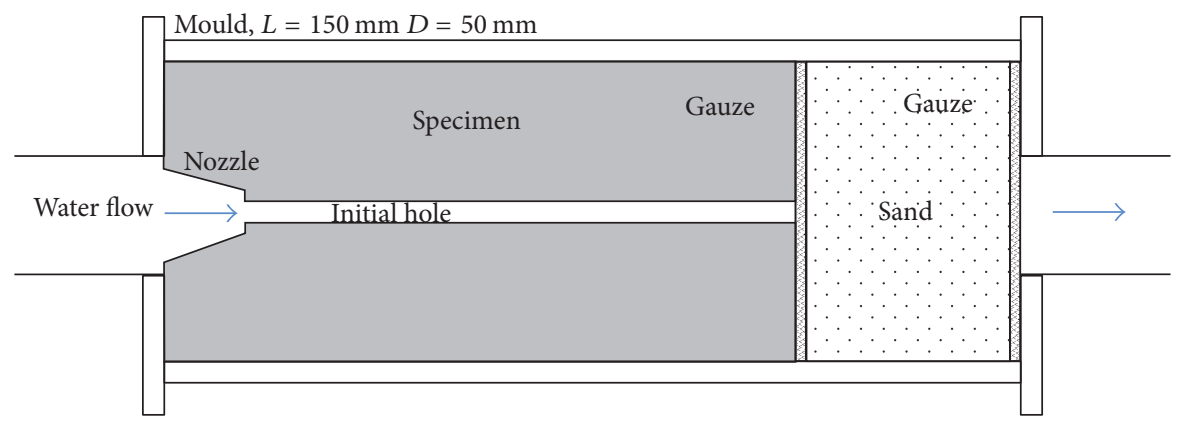

(b)

FIGURE 1: (a) Internal erosion apparatus (left); measurements of water flow and pressure (middle); the controlled water jet (right); (b) detailed erosion device setup schematic.

\section{Experimental Methodology}

2.1. Test Apparatus. The internal erosion test measures the water erosions that take place in the predrilled samples. The test apparatus (Figure 1) is designed to set the specimen mould with an inner diameter of $50 \mathrm{~mm}$ and a length of $150 \mathrm{~mm}$. The pressurized water is provided by a pump using the water inside the black box circularly while the pressure is controlled by a regulator, where the maximum value is limited by about 1.0 bar. Water flow is measured upstream throughout the test using a flow meter, which is accurate to a tenth of a litter per minute. A nozzle is installed at the inlet to control the water jet only passing through the initial hole within the specimen, avoiding leaks along the edge.

For the fills to be used at the exit to fix the sample in the correct position of the mould, rubber rings and plastic foam rings were tried once, but the water impulse was so strong that these fills may cut into the samples. Therefore, sand was chosen to be used at the exit to fix the specimen in the correct position and two gauze screens were used as filters to hold the sand. Trials illustrated that they worked very well since the specimen could be positioned stably without any undesired damage. The detailed device setup is shown in Figure 1(b).

\subsection{Sample Mixture Designs. Two types of sample mixtures} were used in this study. The first one was the cementbentonite mixture and the second one was the cementbentonite mixture produced by using GGBS (BS EN 15167-1) as the cement replacement material, which can bring benefits to strength, setting ability, and reduction in permeability [15]. Because the substitution levels commonly used are relatively high (e.g., Garvin and Hayles [16] recommend 70-80\% GGBS as cement replacement in cement-bentonite slurry) for achieving a given permeability, the proportion of GGBS was adopted as $80 \%$ by weight of the cement component in this study. The cement used (Rugby PFA cement, CEM II/B-V, $32.5 \mathrm{~N}$, supplied by Cemex) contained 20\% PFA (Class F, in accordance with BS EN197-1:2011; BSi 2011 [17]), which is considered to be pozzolanic [18]. The bentonite used was the sodium carbonate activated type (Berkbent 163 Bentonite, supplied by Tolsa UK Ltd.). Therefore, two mixtures were created to represent the mix designs of real seepage barriers in dams that have experienced seepage problems. We defined them as type 1 CB-PFA samples and type 2 CB-GGBS samples. The proportion of bentonite and water remained constant and the two mixtures are specified in Table 1.

2.3. Sample Creation and Preparation. Specimens for erosion tests were formed from slurry to ensure that they were homogenous and fully saturated [19]. The CB-PFA samples and CB-GGBS samples were manufactured broadly according to the procedures of Garvin and Hayles [16]. The bentonite and laboratory-purified water (produced by reverse osmosis) were shaken in a mixer for 30 minutes and the mixture was left to hydrate for a period of 24 hours; the cementitious component was subsequently added to the slurry and it was mixed once again; the slurry was then poured into the cylindrical moulds with an inner diameter of $50 \mathrm{~mm}$ and a length of $150 \mathrm{~mm}$ for consolidation.

In order to create a hole through the sample, we introduced a wire running vertically and centrally from the top cap to the bottom cap throughout the mould. Two weights were attached to the wire at both ends to ensure the wire to be tight during the consolidation process. Once the pouring was finished the decanted slurry was agitated on a vibrating table to de-air it; the final assembled setup is shown in Figure 2(a). Creating the hole within samples in place can reduce the disturbance of the hole wall to a large extent compared to 
TABLE 1: Proportion of the constituent components within the two cement-bentonite mixtures.

\begin{tabular}{|c|c|c|c|c|}
\hline \multicolumn{2}{|c|}{$\begin{array}{l}\text { Mass of the constituent components of the } \\
\text { cement-bentonite samples }\end{array}$} & \multirow[t]{2}{*}{ Mixture } & \multirow{2}{*}{$\begin{array}{c}\text { Proportion of PFA within } \\
\text { cementitious replacement }(\%)\end{array}$} & \multirow{2}{*}{$\begin{array}{l}\text { Proportion of GGBS within } \\
\text { cementitious replacement (\%) }\end{array}$} \\
\hline Component & Mass (g) & & & \\
\hline Water & 1000 & No. 1 & 20 & I \\
\hline $\begin{array}{l}\text { Cement and cement } \\
\text { replacement material }\end{array}$ & 200 & No. 2 & 4 & 80 \\
\hline Bentonite & 40 & & & \\
\hline
\end{tabular}

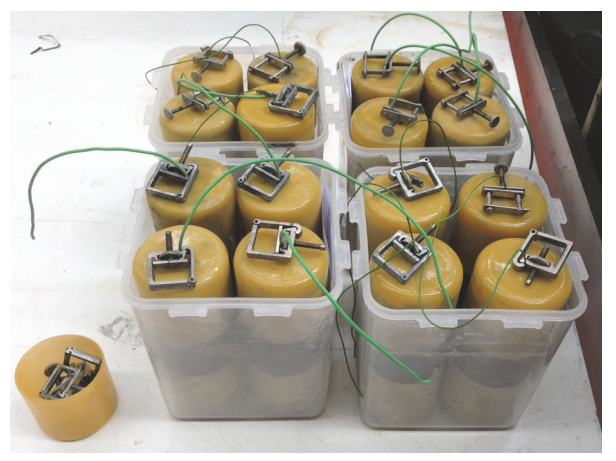

(a)

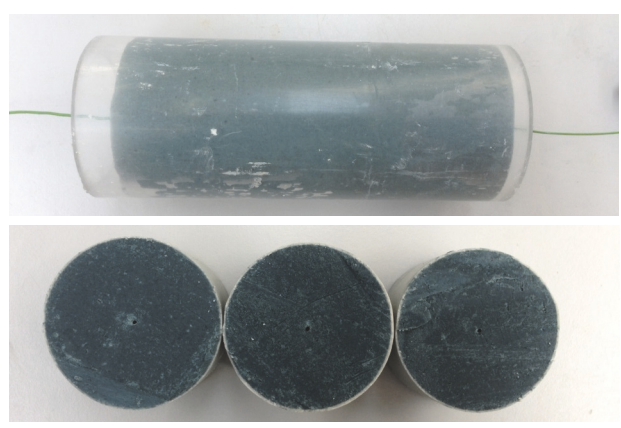

(c)

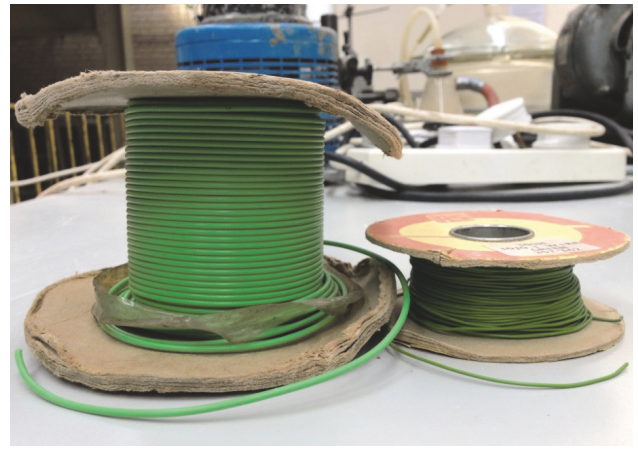

(b)

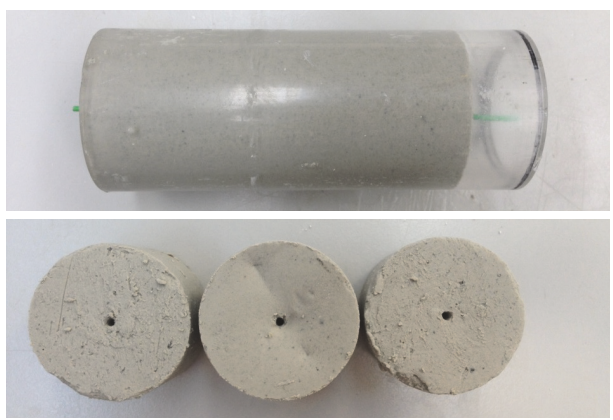

(d)

FIGURE 2: Illustration of the handling of samples; (a) decanted slurry curing within moulds stored in a constant temperature room at a temperature of $5^{\circ} \mathrm{C}$; (b) two sizes of wires were used to create initial holes; (c) CB-GGBS sample with 1 mm initial hole; (d) CB-PFA sample with $2 \mathrm{~mm}$ initial hole.

the practice of inserting the wire afterwards $[12,20]$; thus our method can help to prevent the soil around the hole from the extensive disturbance. In this study, we used two sizes of wires ( $1 \mathrm{~mm}$ and $2 \mathrm{~mm}$ ) to create the initial holes to investigate how different conduits affect the sample erosion.

The samples were cured in a constant temperature room at a temperature of $5^{\circ} \mathrm{C}$ for different curing times, where test ages of $7,14,28$, and 60 days were chosen to assess the performance of the investigated samples since these regimes were commonly used. However, trials showed that the curing process was incomplete for CB-PFA samples of 7 days and the physical properties were still in flux; even the strength was not strong enough to maintain the initial hole to be stable when taking out the wire; thus these samples were eliminated.

When the curing was completed, the wire could be smoothly removed by hand without any rotation since the wire surface did not adhere to the initial hole wall. For checking purpose, the prepared extra samples were cut into sections to confirm that the initial holes made by the wire could be straight, horizontal, and intact along the middle of the samples (Figures 2(c) and 2(d)).
A countersinker of $16.5 \mathrm{~mm}$ diameter was hand drilled into the sample approximately $12 \mathrm{~mm}$ to provide a pilot hole on the lower surface, which was regarded as the inlet face and therefore the nozzle can sit flush towards the initial conduit. When drilling the pilot hole, the countersinker should be inserted slowly and carefully to reduce the disturbance of the sample and avoid the drilled material blocking the hole. Since bleeding could cause the upper face of poured slurry to be varying in physical properties, the cured samples may have wrong length and uneven upper surfaces. Method of casting and trim was selected in preference to casting a sample of the required length; while cutting the sample is not ideal, it was considered to be a preferable alternative [10]. Thus samples were cut to size by a pallet knife to produce the samples with a length of $100 \mathrm{~mm}$ exclusive from the pilot hole.

Because the creation was from batched slurry, individual samples were of varying physical properties, three samples were prepared for each batch, and the mean behaviour of these samples was used to evaluate the characters. Therefore, a total of 126 tests were conducted and Table 2 presents the groups of the tested samples, where the different material 
TABLE 2: Summary of experiments of different regimes.

\begin{tabular}{|c|c|c|c|c|c|c|c|c|c|c|c|c|c|}
\hline \multirow{3}{*}{ Sample types } & \multirow{3}{*}{ Initial holes } & \multicolumn{12}{|c|}{ Number of samples investigated } \\
\hline & & \multicolumn{4}{|c|}{ Eroded for 1 hour } & \multicolumn{4}{|c|}{ Eroded for 2 hours } & \multicolumn{4}{|c|}{ Eroded for 3 hours } \\
\hline & & $\begin{array}{c}7 \\
\text { days }\end{array}$ & $\begin{array}{c}14 \\
\text { days }\end{array}$ & $\begin{array}{c}28 \\
\text { days }\end{array}$ & $\begin{array}{c}60 \\
\text { days }\end{array}$ & $\begin{array}{c}7 \\
\text { days }\end{array}$ & $\begin{array}{c}14 \\
\text { days }\end{array}$ & $\begin{array}{c}28 \\
\text { days }\end{array}$ & $\begin{array}{c}60 \\
\text { days }\end{array}$ & $\begin{array}{c}7 \\
\text { days }\end{array}$ & $\begin{array}{c}14 \\
\text { days }\end{array}$ & $\begin{array}{c}28 \\
\text { days }\end{array}$ & $\begin{array}{c}60 \\
\text { days }\end{array}$ \\
\hline \multirow{2}{*}{ CB-PFA } & $1 \mathrm{~mm}$ & I & 3 & 3 & 3 & I & 3 & 3 & 3 & I & 3 & 3 & 3 \\
\hline & $2 \mathrm{~mm}$ & l & 3 & 3 & 3 & l & 3 & 3 & 3 & l & 3 & 3 & 3 \\
\hline \multirow{2}{*}{ CB-GGBS } & $1 \mathrm{~mm}$ & 3 & 3 & 3 & 3 & 3 & 3 & 3 & 3 & 3 & 3 & 3 & 3 \\
\hline & $2 \mathrm{~mm}$ & 3 & 3 & 3 & 3 & 3 & 3 & 3 & 3 & 3 & 3 & 3 & 3 \\
\hline
\end{tabular}
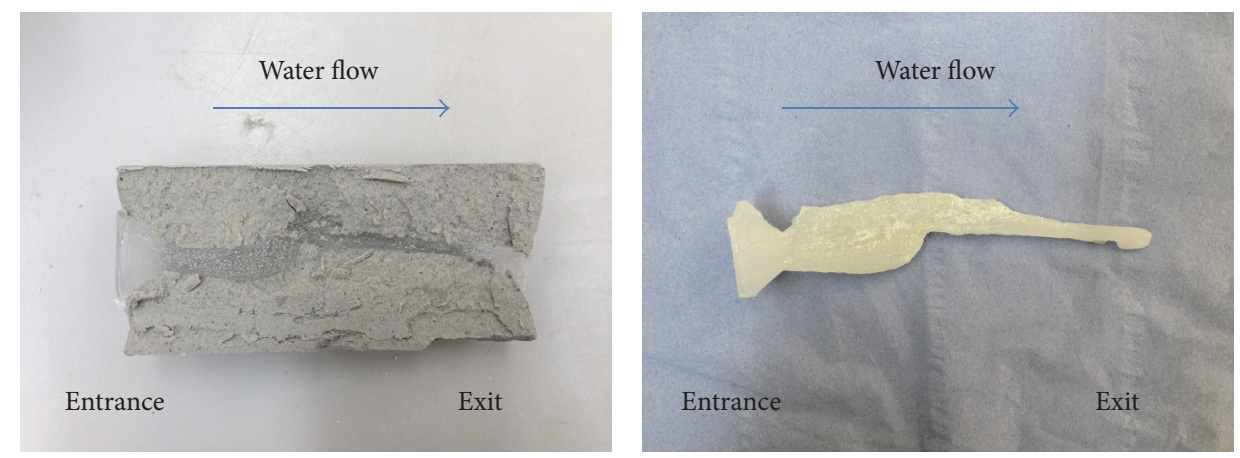

FIGURE 3: Cross-section showing the cast of an eroded cavity.

component, curing period, erosion time, and size of initial holes are investigated.

2.4. Data Collection and Erosion Calculation. We set the given flow rate to be $3 \mathrm{~L} / \mathrm{min}$ for the designed erosion durations of 60,120 , and 180 minutes, respectively. Based on the law of volumetric flow rate, the flow velocity $(v)$ can be obtained as the quotient of flow rate $(Q)$ to the cross-area $(A)$ that fluid travels through, as specified $v=Q / A$. Thus the flow velocity of the $1 \mathrm{~mm}$ initial hole is 4 times larger than that of the $2 \mathrm{~mm}$ initial hole at the beginning. After the samples were subjected to the pinhole erosion test, the liquid wax was chosen to cast the eroded conduits to provide undisturbed images of the erosion cavity. The samples were positioned within the moulds for pouring the liquid wax and allowing the wax to flow from the entrance and fully occupy the eroded holes. It was required to give some time to ensure the exit to be sealed before casting the whole conduit. Then the samples were disassembled to extract the cast to be inspected and photographed for the erosion patterns. Figure 3 shows a typical example of the cross-section of an eroded cavity after test.

The cast was washed carefully to remove the sticking material and dried before measuring the weight. In this process, the cast of nozzle was rejected from this measurement. It was straightforward to work out the erosion volume of the sample via dividing the cast weight by the wax density (tested with a value of $0.8 \mathrm{~g} / \mathrm{cm}^{3}$ ).

\section{Results}

One example of the 14-day CB-PFA sample being eroded for 2 hours is illustrated in Figure 4(a), which shows the crosssection of the initial hole before and after test for both entrance and exit where the $2 \mathrm{~mm}$ diameter hole became $9.5 \mathrm{~mm}$ at the entrance. The cast of the eroded cavity (Figure 4(b)) was extracted to the black silhouette (Figure 4(c)) to clearly illustrate the shape changes of the initial conduit. In addition, a part of the investigated samples, regardless of the material types, exhibited brittle transverse microcracks during eroding (Figure 4(d)), possibly because the water jet was so intense, thereby resulting in the formation of these microcracks through the sample.

For CB-PFA samples, if the curing period was 14 and 28 days, microcracks occurred in all test specimens. If curing period reached 60 days, test specimens indicated basically the same performance; when erosion time lasted for 1 hour and 2 hours, for initial hole of $1 \mathrm{~mm}$, only one out of six test specimens indicated microcracks; for initial hole of $2 \mathrm{~mm}$, two out of six test specimens indicated microcracks; when erosion time lasted for 3 hours, all test specimens indicated microcracks. For CB-GGBS samples, if the curing period was 7 days, microcracks occurred in all test specimens. If curing period was 14 to 60 days, test specimens indicated basically the same performance. In other words, when erosion time lasted for 1 hour and 2 hours, for initial hole of $1 \mathrm{~mm}, 83.3 \%$ of test specimens did not indicate microcracks; for initial hole of $2 \mathrm{~mm}, 72.2 \%$ of test specimens did not indicate microcracks. 


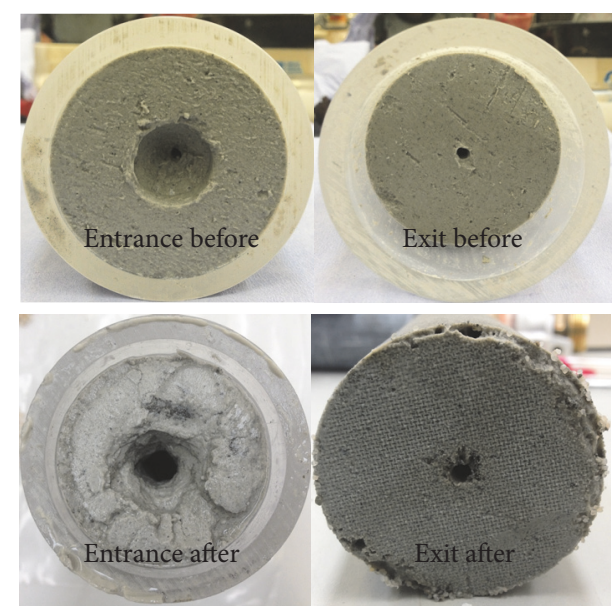

(a)

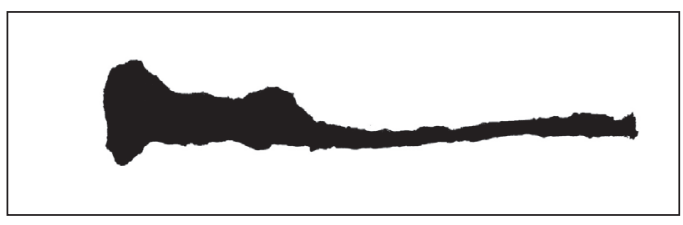

(c)

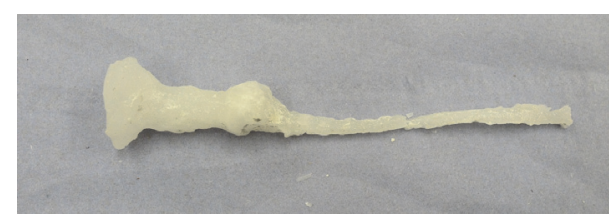

(b)

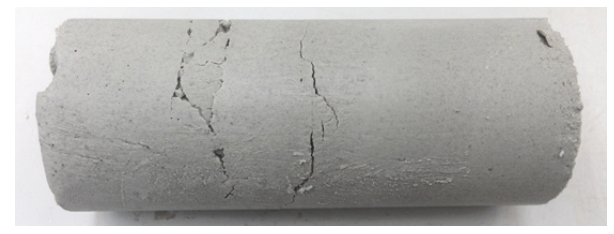

(d)

Figure 4: Example of the 14 days CB-PFA sample being eroded for 2 hours. (a) Surfaces of entrance and exit of the hole before and after test; (b) cast of the eroded cavity; (c) extracted black silhouette of the cast; (d) brittle transverse microcracks appeared during eroding.

When erosion time increased to 3 hours, all test specimens indicated microcracks.

To sum up, test specimens with smaller initial holes were less likely to indicate microcracks than test specimens with larger initial holes. But their differences were not significant. However, there was an apparent trend of decreasing microcrack widths with curing duration but increasing crack widths with erosion time. With the increase of the curing, both types of samples became stiffer and stronger as the microcrack widths reduced; for instance, there were not any microcracks for both samples cured for 60 days after 1-hour erosion; however, as the erosion time increased to 3 hours, the brittle microcracks appeared again. Although there was water in the microcracks, the water flow passes mainly through the initial holes that could guarantee the test purpose.

We defined the erosion percentage (\%) as the ratio of the eroded material volume to the original volume of the specimen. The original volume was calculated according to the sample geometry and the eroded volume was obtained via dividing the cast weight by the wax density. The erosion percentage is specified in the following:

$$
P_{\text {erosion }}=\frac{V_{\text {eroded }}}{V_{\text {original }}}=\frac{M_{\text {eroded }} / \rho_{\text {wax }}}{V_{\text {original }}} .
$$

When we calculate the original volumes, the volume of the initial holes should be excluded. The summary of the erosion percentages for the CB-PFA and CB-GGBS samples is listed in Table 3.

The relationships between erosion percentage of the investigated CB-PFA samples and CB-GGBS samples against erosion time are shown in Figure 5. Each point corresponds to the mean value out of three tests; that is, Figure 5(a) shows the results of 54 tests for CB-PFA samples and Figure 5(b) shows the results of 72 tests for CB-GGBS samples. According to the erosion percentage and the shape of the conduit cast, there was an overall increase in erosion with increased erosion time for both types of samples. Meanwhile, the trend also showed that material was eroded quickly at the beginning of the test and then slowed down with time.

With respect to the CB-PFA samples cured for 60 days, there was no obvious difference in the erosion percentage between 1-hour erosion and 3-hour erosion. As for the CBGGBS samples, the conduits of 7-day specimens were witnessed to widen when the erosion time approached/exceeded 2 hours. Conversely, samples cured for more than 14 days exhibited similar behaviour that the impact of erosion time on the erosion percentage reduced to a certain degree.

From Figure 6, it is apparent that if the curing time increases, the erosion percentages for all cases drop down. Specifically, the difference of erosion percentage between each curing interval reduced, meaning that the erosion rate was reduced as the curing increased for the given barrier materials. However, the downward trend of the CB-GGBS samples was more obvious than that of the CB-PFA samples. In addition, the erosion percentage of the CB-PFA was approximately two times higher than that of the CB-GGBS for the same curing period. Even CB-PFA samples cured for 28 days did exceed the erosion percentage for CB-GGBS samples cured for only 14 days. As the curing period increased to 60 days, the difference in the erodibility between these two types reduced that the erosion percentage of the former was as approximately 1.3 to 1.7 times as that of the latter. This 
TABLE 3: Summary of the erosion percentages for the CB-PFA samples and the CB-GGBS samples.

\begin{tabular}{|c|c|c|c|c|}
\hline Number & CB-PFA & Erosion percentage (\%) & CB-GGBS & Erosion percentage (\%) \\
\hline (1) & 1 & 1 & $1 \mathrm{~mm}-7$ days- $1 \mathrm{~h}$ & 2.331 \\
\hline (2) & l & l & $1 \mathrm{~mm}-7$ days- $2 \mathrm{~h}$ & 3.675 \\
\hline (3) & l & l & $1 \mathrm{~mm}-7$ days-3 h & 4.671 \\
\hline (4) & l & l & $2 \mathrm{~mm}-7$ days- $1 \mathrm{~h}$ & 1.639 \\
\hline (5) & l & l & $2 \mathrm{~mm}-7$ days- $2 \mathrm{~h}$ & 1.900 \\
\hline (6) & l & l & $2 \mathrm{~mm}-7$ days $-3 \mathrm{~h}$ & 1.917 \\
\hline (7) & $1 \mathrm{~mm}-14$ days- $1 \mathrm{~h}$ & 1.161 & $1 \mathrm{~mm}-14$ days- $1 \mathrm{~h}$ & 0.197 \\
\hline (8) & $1 \mathrm{~mm}-14$ days- $2 \mathrm{~h}$ & 1.348 & $1 \mathrm{~mm}-14$ days- $2 \mathrm{~h}$ & 0.426 \\
\hline (9) & $1 \mathrm{~mm}-14$ days- $3 \mathrm{~h}$ & 1.470 & $1 \mathrm{~mm}-14$ days- $3 \mathrm{~h}$ & 0.625 \\
\hline$(10)$ & $2 \mathrm{~mm}-14$ days- $1 \mathrm{~h}$ & 0.947 & $2 \mathrm{~mm}-14$ days- $1 \mathrm{~h}$ & 0.725 \\
\hline (11) & $2 \mathrm{~mm}-14$ days- $2 \mathrm{~h}$ & 1.705 & $2 \mathrm{~mm}-14$ days $-2 \mathrm{~h}$ & 0.842 \\
\hline (12) & $2 \mathrm{~mm}-14$ days- $3 \mathrm{~h}$ & 2.333 & $2 \mathrm{~mm}-14$ days $-3 \mathrm{~h}$ & 0.973 \\
\hline (13) & $1 \mathrm{~mm}-28$ days- $1 \mathrm{~h}$ & 0.790 & $1 \mathrm{~mm}-28$ days- $1 \mathrm{~h}$ & 0.121 \\
\hline (14) & $1 \mathrm{~mm}-28$ days- $2 \mathrm{~h}$ & 1.197 & $1 \mathrm{~mm}-28$ days $-2 \mathrm{~h}$ & 0.129 \\
\hline (15) & $1 \mathrm{~mm}-28$ days- $3 \mathrm{~h}$ & 1.227 & $1 \mathrm{~mm}-28$ days $-3 \mathrm{~h}$ & 0.460 \\
\hline (16) & $2 \mathrm{~mm}-28$ days- $1 \mathrm{~h}$ & 0.421 & $2 \mathrm{~mm}-28$ days $-1 \mathrm{~h}$ & 0.254 \\
\hline (17) & $2 \mathrm{~mm}-28$ days $-2 \mathrm{~h}$ & 0.587 & $2 \mathrm{~mm}-28$ days $-2 \mathrm{~h}$ & 0.540 \\
\hline (18) & $2 \mathrm{~mm}-28$ days $-3 \mathrm{~h}$ & 1.007 & $2 \mathrm{~mm}-28$ days $-3 \mathrm{~h}$ & 0.653 \\
\hline (19) & $1 \mathrm{~mm}-60$ days- $1 \mathrm{~h}$ & 0.144 & $1 \mathrm{~mm}-60$ days- $1 \mathrm{~h}$ & 0.067 \\
\hline$(20)$ & $1 \mathrm{~mm}-60$ days- $2 \mathrm{~h}$ & 0.147 & $1 \mathrm{~mm}-60$ days $-2 \mathrm{~h}$ & 0.087 \\
\hline$(21)$ & $1 \mathrm{~mm}-60$ days-3 h & 0.152 & $1 \mathrm{~mm}-60$ days $-3 \mathrm{~h}$ & 0.124 \\
\hline$(22)$ & $2 \mathrm{~mm}-60$ days $-1 \mathrm{~h}$ & 0.343 & $2 \mathrm{~mm}-60$ days $-1 \mathrm{~h}$ & 0.215 \\
\hline (23) & $2 \mathrm{~mm}-60$ days $-2 \mathrm{~h}$ & 0.541 & $2 \mathrm{~mm}-60$ days $-2 \mathrm{~h}$ & 0.457 \\
\hline$(24)$ & $2 \mathrm{~mm}-60$ days $-3 \mathrm{~h}$ & 0.562 & $2 \mathrm{~mm}-60$ days $-3 \mathrm{~h}$ & 0.547 \\
\hline
\end{tabular}

indicated that the inclusion of cementitious materials within the slurry will clearly result in changing physical properties; samples containing GGBS have a higher rate of strength increase with curing; that is, in order to achieve a certain performance in resisting water, the CB-GGBS samples require a shorter curing period.

The sizes of initial holes may affect the erosion situation varying from the sample curing regardless of the material types. For juvenile samples, the erosion percentage of samples with $1 \mathrm{~mm}$ initial hole was approximately twice higher than that of the one with $2 \mathrm{~mm}$ initial hole. By contrast, when the curing duration was enough, samples with larger initial holes would experience more severe erosion.

\section{Discussion and Conclusion}

Normally before the construction of a seepage barrier, material that is to be used should be subjected to a variety of tests to determine its properties to assess its suitability. The erodibility of material is controlled by two factors, the strength of material, or its erosion resistance, and the flow regime of the eroding fluid, that is, sufficient seepage flow to overcome a critical shear strength between particles for erosion and transportation [7, 21-24]. The strength is correlated to the cementitious properties of replacement and curing period while the seepage flow is corresponding to the erosion time.
The cement-bentonite mixtures containing GGBS have a higher strength and stiffness in comparison with the behaviour of CB-PFA samples, highlighting the potential advantage with the inclusion of GGBS in the cementbentonite mixtures, which could bring great benefits to slurry loss and in-trench mix curing. Curing period is significant to the sample performance. Juvenile samples had significant erosion percentage; however, an apparent downward trend of the erosion rate was obtained for the samples cured for 28 days or longer; when the samples were cured for 60 days, there were even no obvious changes in the shape of the initial conduits. This suggests that enough curing period for a barrier could improve the ability to avoid the increases of hydraulic conductivity in the macrofabric of the barrier that may cause the fail in its primary function.

Since the flow velocity controls the shear stress [23] and for a constant flow rate $(Q)$, initially the velocity within a smaller crack is higher and more erosive to the barrier material to be developed into pipes. The continued flow along the pipes will further propagate the erosion, which is considered to be the mechanism of the concern in several existing seepage barriers [25]. With the increase of the cross-section area of the initial conduit during erosion, the flow velocity reduces; this reduced velocity will result in a decrease of the shear stress and thus a decline in erosion rate as well. Therefore, even if a crack on a barrier could be eroded under a certain gradient, the crack width will initially increase, but, 


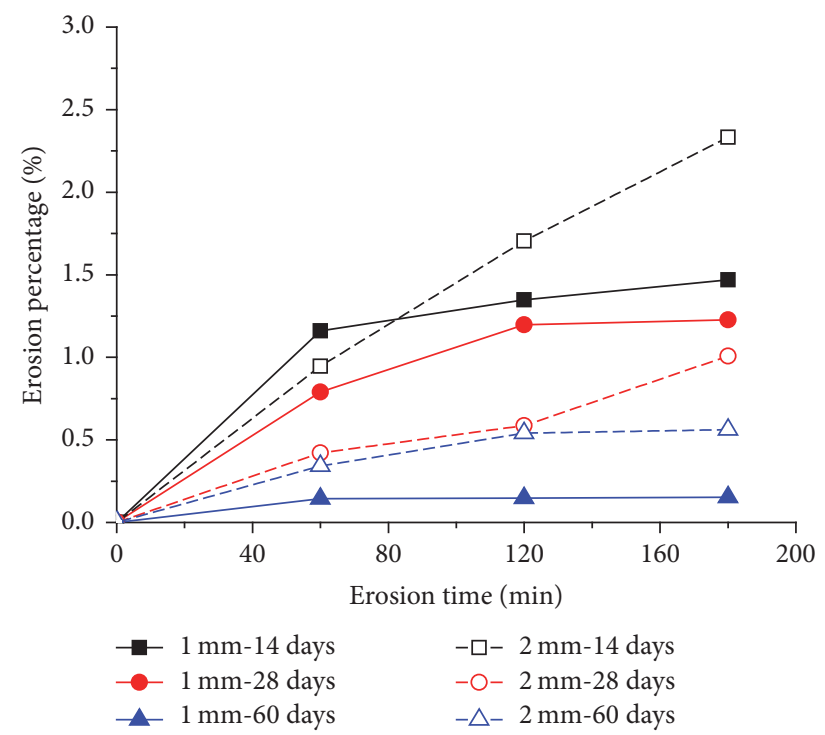

(a)

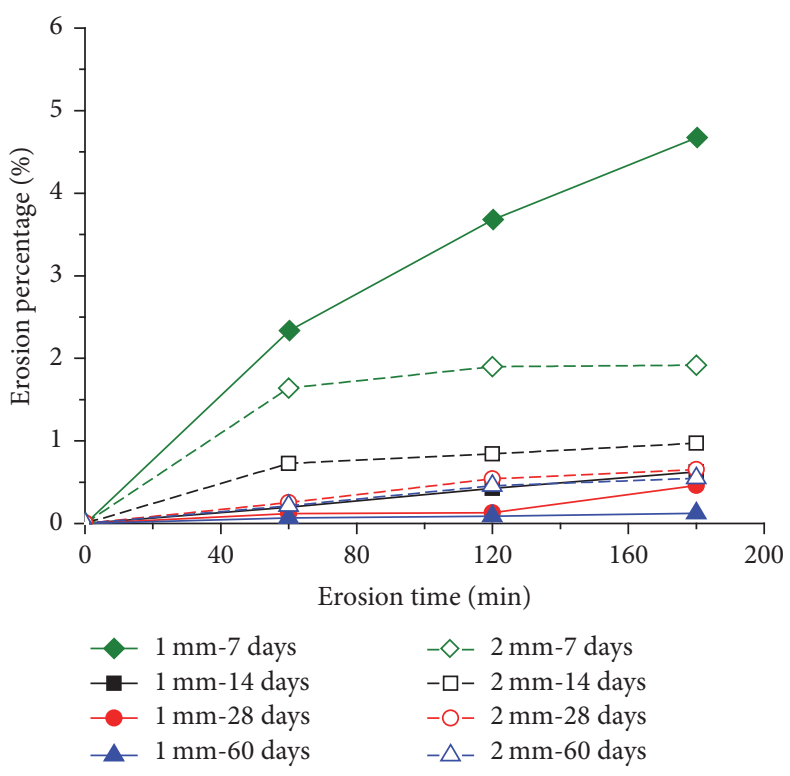

(b)

FIGURE 5: Erosion percentage against erosion time for (a) CB-PFA samples and (b) CB-GGBS samples.

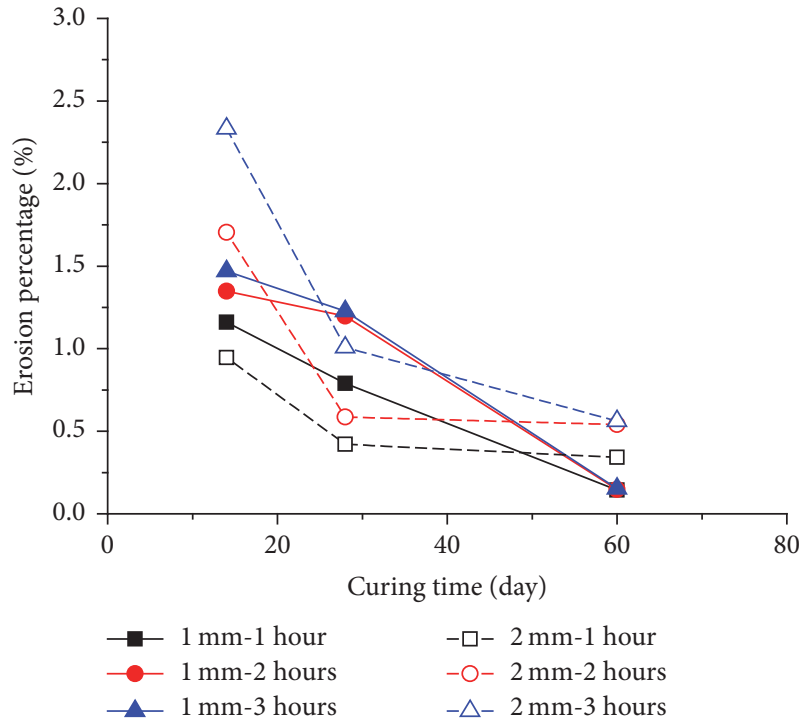

(a)

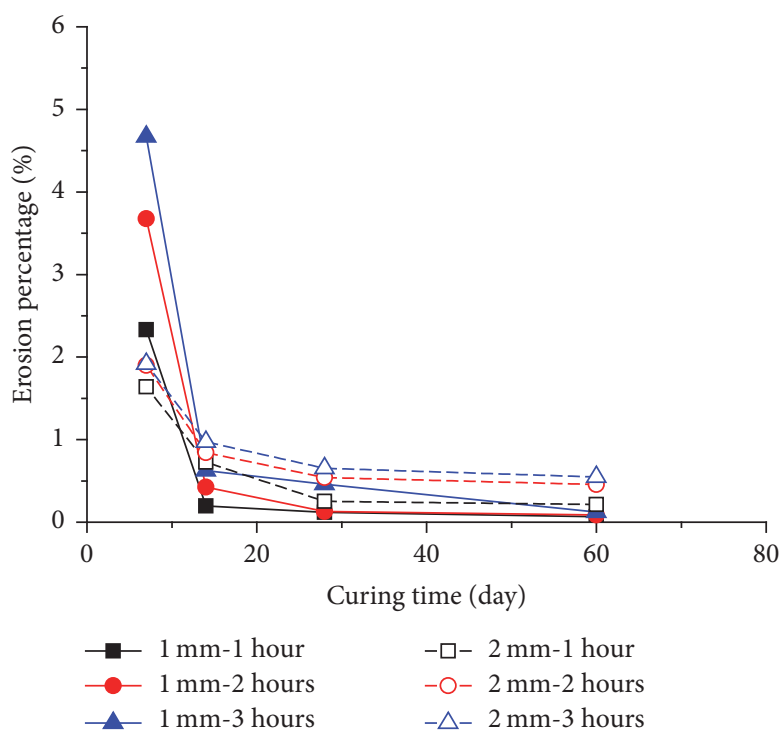

(b)

FIGURE 6: Erosion percentage against curing time for (a) CB-PFA samples and (b) CB-GGBS samples.

at some point in time, the width will be stabilised as the water velocity decreases in the crack.

With respect to the issue of how different sizes of initial cracks affect the barrier behaviours against eroding, the material erodibility and the water velocity inside the mass should be considered concurrently. When the curing duration is incomplete, the flow velocity dominates the erosion of the barrier that smaller cracks can cause higher erosion percentage. However, with the increase of the critical shear stress in correlation with the curing, the difference between the shear stress caused by velocity and the critical stress reduced, meaning that the dominant factor affecting the erosion is changed. On the other hand, the generated pipes with larger diameters can provide more particles to be detached from the conduit wall compared with pipes of smaller diameters. The more particles having the potential to be detached, the higher erosion percentage to be caused. However, to what extent the larger initial hole may affect the erosion situation is not easy to ascertain, while, according to Hubbe [23], no matter how small is the applied force, the particles will be released after a characteristic length of time; thus, this might be a timerelated issue which should be studied further. 


\section{Conflicts of Interest}

The authors declare that they have no conflicts of interest.

\section{Acknowledgments}

This research has been supported by the State Key Program of National Natural Science Foundation of China (Grant no. U1434210), the National Natural Science Foundation of China (Grant no. 51778046), the National Natural Science Foundation of China (Grant no. 51278045), and the Project of Shenzhen Metro Group Co., Ltd. (no. SZ-CGM-KY001/2014).

\section{References}

[1] S. A. Jefferis, "The origins of the slurry trench cut-off and a review of cement-bentonite cut-off walls in the UK," in Proceedings of the International Containment Technology Conference and Exhibition, St. Petersburg, Fla, USA, 1997.

[2] S. M. Opdyke and J. C. Evans, "Slag-cement-bentonite slurry walls," Journal of Geotechnical and Geoenvironmental Engineering, vol. 131, no. 6, pp. 673-681, 2005.

[3] E. Sinco, M. Xiao, L. M. Owaidat, and L. Smith, "Slurry induced piping progression of a sand," in Proceedings of the 5th International Conference on Scour and Erosion, pp. 408-417, San Francisco, Calif, USA, November 2010.

[4] C. F. Wan and R. Fell, "Investigation of rate of erosion of soils in embankment dams," Journal of Geotechnical and Geoenvironmental Engineering, vol. 130, no. 4, pp. 373-380, 2004.

[5] R. S. Govindaraju, L. N. Reddi, and S. K. Kasavaraju, "A physically based model for mobilization of kaolinite particles under hydraulic gradients," Journal of Hydrology, vol. 172, no. 1, pp. 331-350, 1995.

[6] J. A. A. Jones, J. M. Richardson, and H. J. Jacob, "Factors controlling the distribution of piping in Britain: A reconnaissance," Geomorphology, vol. 20, no. 3-4, pp. 289-306, 1997.

[7] L. N. Reddi and M. V. Bonala, "Analytical solution for fine particle accumulation in soil filters," Journal of Geotechnical and Geoenvironmental Engineering, vol. 123, no. 12, pp. 1143-1152, 1997.

[8] J. C. Evans, A. R. Dawson, and S. Opdyke, "Slurry walls for groundwater control: a comparison of UK and US practice," in Proceedings of the ASCE/PENNDOT Central PA Geotechnical Conference, 2002.

[9] Institution of Civil Engineers (ICE), Specification for the Construction of Slurry Trench Cut-off Walls, Thomas Telford, London, UK, 1999.

[10] A. C. D. Royal, Y. Makhover, S. Moshirian, and D. Hesami, "Investigation of cement-bentonite slurry samples containing PFA in the UCS and triaxial apparatus," Geotechnical and Geological Engineering, vol. 31, no. 2, pp. 767-781, 2013.

[11] L. K. Sear, Properties and Use of Coal Fly Ash: A Valuable Industrial by-Product, Thomas Telford, London, UK, 2001.

[12] J. L. Sherard, E. F. Steele, R. S. Decker, and E. F. Steele, "Pinhole test for identifying dispersive soils," Journal of the Geotechnical Engineering Division, vol. 102, no. 1, pp. 69-85, 1976.

[13] C. F. Wan and R. Fell, "Investigation of internal erosion and piping of soils in embankment dams by the slot erosion test and the hole erosion test," UNICIV Report No R-412, University of New South Wales, New South Wales, Australia, 2002.
[14] N. Benahmed and S. Bonelli, "Investigating concentrated leak erosion behaviour of cohesive soils by performing hole erosion tests," European Journal of Environmental and Civil Engineering, vol. 16, no. 1, pp. 43-58, 2012.

[15] M. Williams and G. S. Ghataora, "Effect of fibre reinforcement on the properties of ground granulated blast furnace slagcement-bentonite slurry," Studia Geotechnica et Mechanica, vol. 33, no. 4, pp. 63-83, 2011.

[16] S. L. Garvin and C. S. Hayles, "Chemical compatibility of cement-bentonite cut-off wall material," Construction and Building Materials, vol. 13, no. 6, pp. 329-341, 1999.

[17] BSI, BS EN 197-1:2011. Cement Part 1: Composition, Specifications and Conformity Criteria for Common Cements, The British Standards Institution, 2011.

[18] S. H. Gebler and P. Klieger, "Effect of fly ash on physical properties of concrete," Journal of the American Concrete Institute, vol. 83, no. 2, p. 328, 1986.

[19] J. H. Atkinson, J. A. Charles, and H. K. Mhach, "Examination of erosion resistance of clays in embankment dams," Quarterly Journal of Engineering Geology and Hydrogeology, vol. 23, no. 2, pp. 103-108, 1990.

[20] C. C. Hird and V. J. Moseley, "Model study of seepage in smear zones around vertical drains in layered soil," Geotechnique, vol. 50, no. 1, pp. 89-97, 2000.

[21] R. Flores-Berrones and N. P. Lopez-Acosta, "Internal erosion due to water flow through earth dams and earth structures," in Soil Erosion Studies, D. Godone, Ed., InTech, 2011.

[22] L. A. Clark and T. M. Wynn, "Methods for determining streambank critical shear stress and soil erodibility: Implications for erosion rate predictions," Transactions of the ASABE, vol. 50, no. 1, pp. 95-106, 2007.

[23] M. A. Hubbe, "Theory of detachment of colloidal particles from flat surfaces exposed to flow," Colloids and Surfaces, vol. 12, no. C, pp. 151-178, 1984.

[24] J. R. Talbot, "The mechanics of cracking in embankment dams," in Fracture Mechanics Applied to Geotechnical Engineering: Proceedings of Sessions Sponsored by the Geotechnical Engineering Division of the American Society of Civil Engineers in Conjunction with the ASCE National Convention, E. Vallejo and R. Y. Liang, Eds., American Society of Civil Engineers, pp. 118130, Atlanta, Ga, USA, 1994.

[25] J. D. Rice and J. M. Duncan, "Deformation and cracking of seepage barriers in dams due to changes in the pore pressure regime," Journal of Geotechnical and Geoenvironmental Engineering, vol. 136, no. 1, pp. 16-25, 2010. 

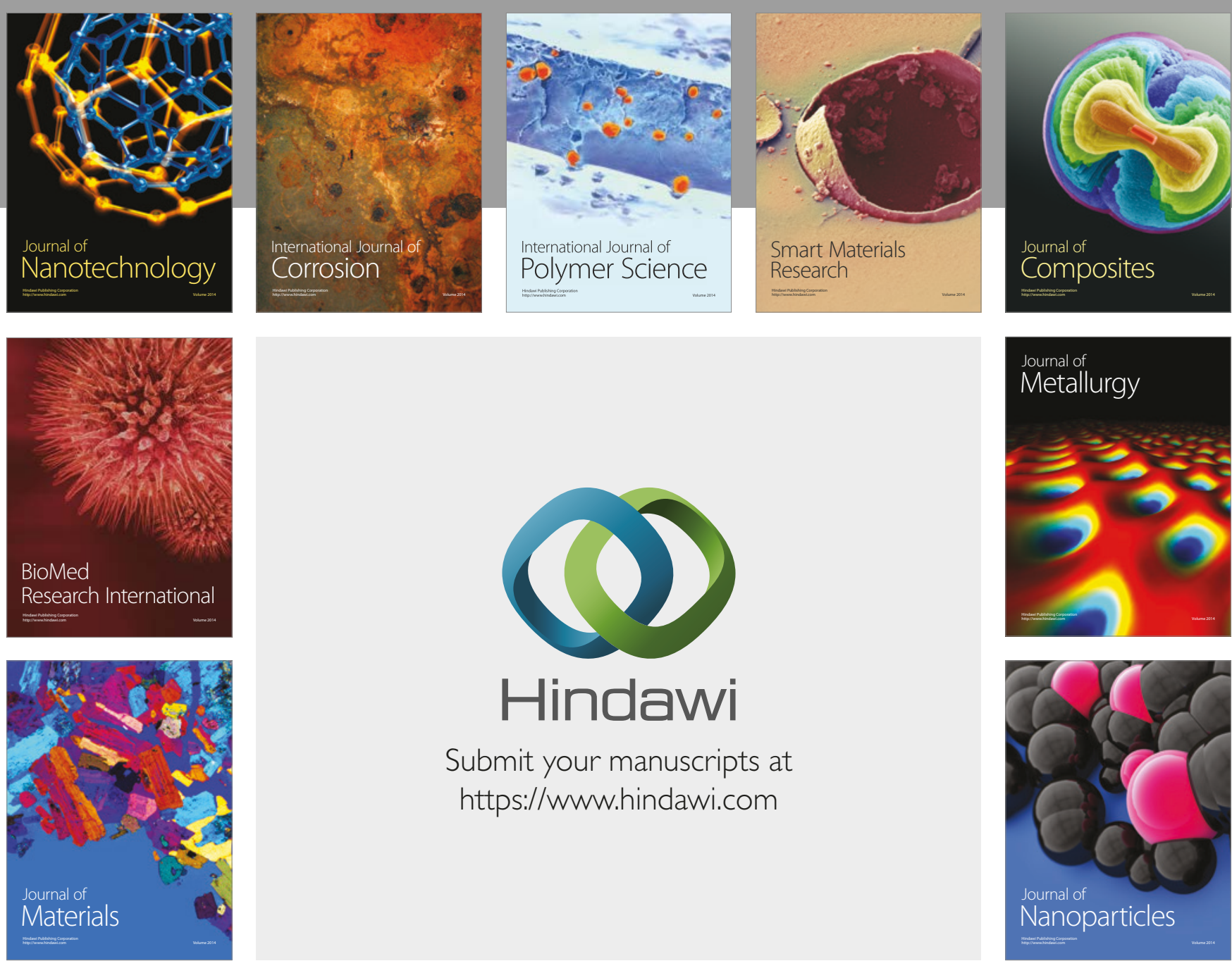

\section{Hindawi}

Submit your manuscripts at

https://www.hindawi.com
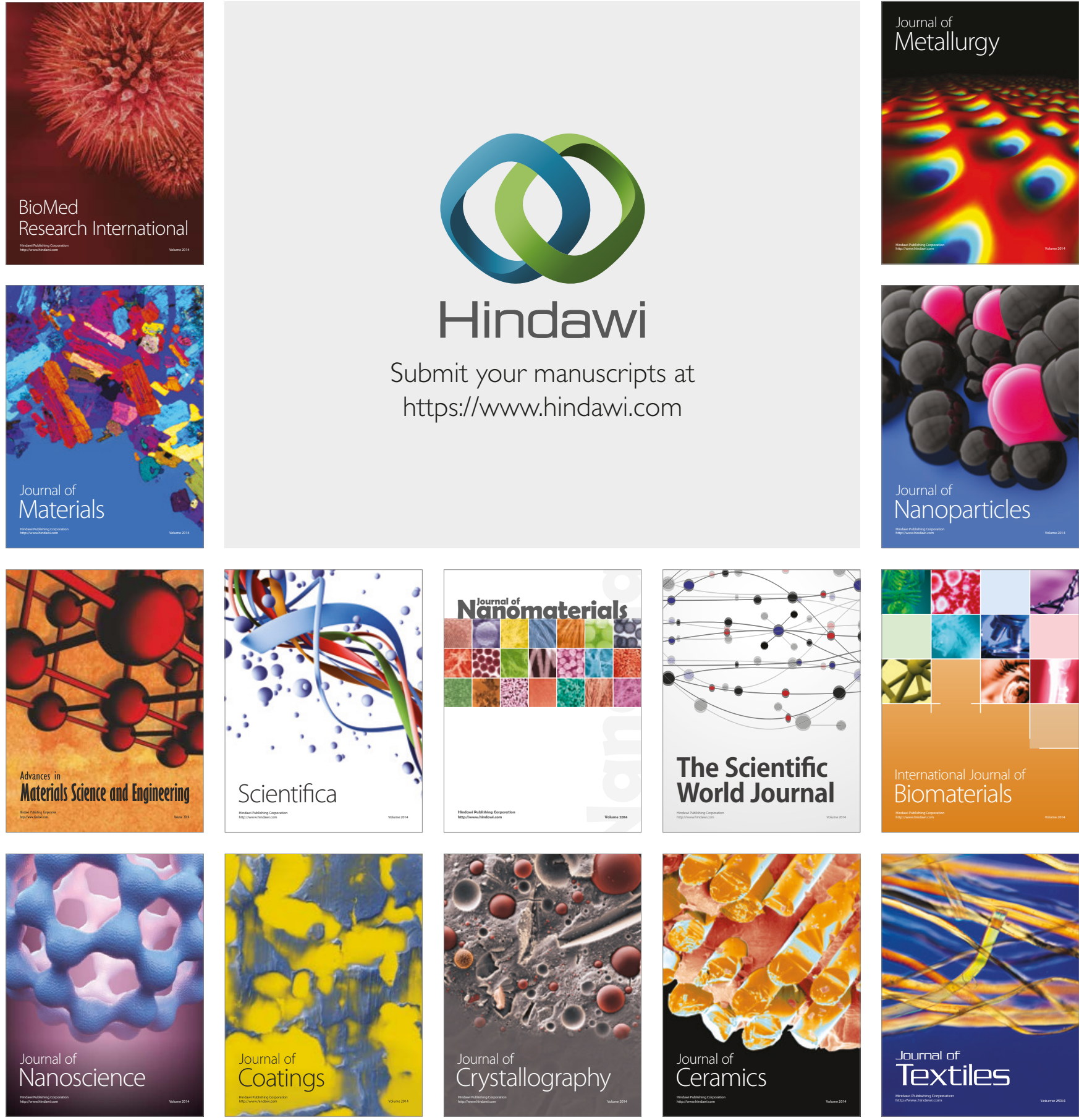

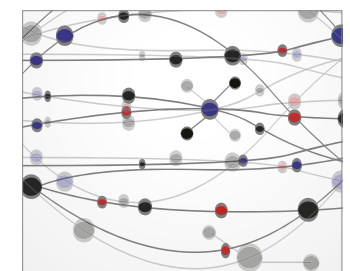

The Scientific World Journal
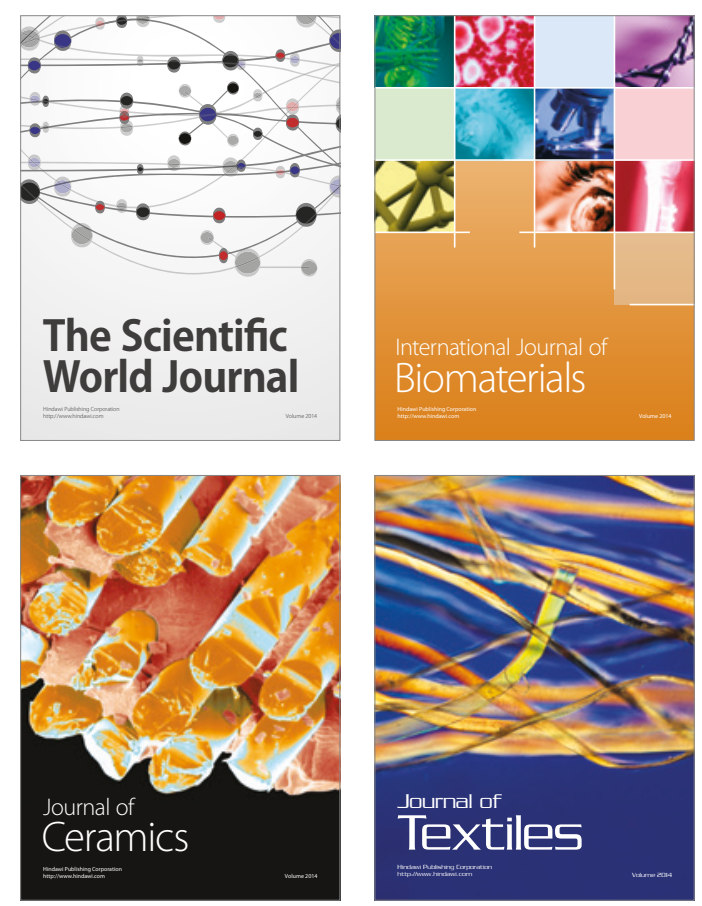